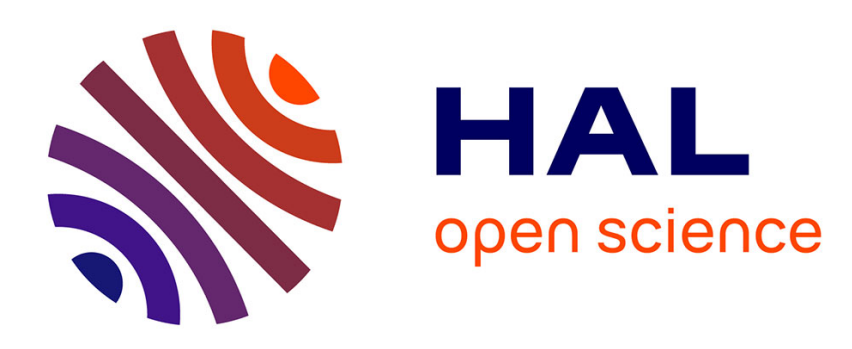

\title{
The Use of Goal Modelling for the Analysis of Value Co-Creation in Collaborative Networks
}

Garyfallos Fragidis

\section{To cite this version:}

Garyfallos Fragidis. The Use of Goal Modelling for the Analysis of Value Co-Creation in Collaborative Networks. 22nd Working Conference on Virtual Enterprises (PRO-VE 2021), Nov 2021, Saint-Etienne, France. pp.354-361, 10.1007/978-3-030-85969-5_32 . emse-03339419

\section{HAL Id: emse-03339419 \\ https://hal-emse.ccsd.cnrs.fr/emse-03339419}

Submitted on 24 Nov 2021

HAL is a multi-disciplinary open access archive for the deposit and dissemination of scientific research documents, whether they are published or not. The documents may come from teaching and research institutions in France or abroad, or from public or private research centers.
L'archive ouverte pluridisciplinaire HAL, est destinée au dépôt et à la diffusion de documents scientifiques de niveau recherche, publiés ou non, émanant des établissements d'enseignement et de recherche français ou étrangers, des laboratoires publics ou privés. 


\title{
The Use of Goal Modelling for the Analysis of Value Co-Creation in Collaborative Networks
}

\author{
Garyfallos Fragidis \\ International Hellenic University, Faculty of Economics and Business, \\ Terma Magnisias Campus, 62124 Serres, Greece \\ gary.fragidis@ihu.gr
}

\begin{abstract}
Collaborative networks engage their members in sharing resources, competencies and responsibilities in order to attain advanced results or common goals. This paper studies the relationship between these two key concepts in collaborative networks, goals and collaborative value creation. Goal achievement can be seen as a value creation behavior and as a value co-creation procedure since it is based on the collaboration and the interdependencies between actors. Therefore, goal modelling can be used for the analysis of value co-creation in collaborative settings. The paper develops a goal meta-model that describes the key concepts of value co-creation. The proposed goal meta-model can serve to the better understanding of the value creation process, the analysis of value co-creation in real-world cases and the design and implementation of digital systems that enable value co-creation.
\end{abstract}

Keywords: goal model, requirement analysis, requirement engineering, value creation, value co-creation, collaborative network, service design

\section{Introduction}

Business organizations collaborate with partners and quite often form collaborative networks in order to acquire information, knowledge, competencies and resources that exist out of their boundaries. There are different forms of collaborative networks that can have various objectives, such as sharing information among their members, seeking the alignment of their activities and operations in order to achieve improved efficiency and engaging their members in sharing resources, competencies and responsibilities in order to attain advanced results or common goals [1]. In general, businesses participate in collaborative networks and collaborate with others in order to serve better their goals or pursue mutual benefits and common goals.

Two key concepts in the study of collaborative networks are the attainment of the goals of their members and the collaboration in the creation of value - that could be termed also 'value co-creation'. Participation in collaborative networks absolutely serves the achievement of certain goals of their members, either their common goals or individual goals. The attainment of goals and the collaborative value creation are closely related to each other as the goals have or bring value to the members of the network and/or their stakeholders and their attainment is certainly a collaborative 
procedure. In particular, value creation is a direct collaborative procedure when the members collaborate and coordinate their activities for the creation of value in concert, while it is an indirect collaborative procedure when they exchange or share resources and information so as to enable their partners to create value.

In this paper we focus on these two key concepts in collaborative networks, goals and value creation, in order to study their relationship and suggest a method for the analysis of value co-creation as a goal attainment procedure. In this realm, the paper describes how goal modelling techniques can be applied for the analysis of value creation in collaborative networks and presents a meta-model that integrates goal attainment and value creation in the same analytical framework. The proposed metamodel can serve as a general pattern both for the study of the relationships between actors and the various interdependencies that are present in value creation in collaborative networks and for the development of particular goal models that describe value co-creation in particular cases and settings.

The research approach employs methods from goal-oriented requirements engineering (GORE) for the analysis of goals and the modelling of goal structures in collaborative networks. For the requirements of the value creation procedure, we use the contemporary literature of service management, which regards value creation as a collaborative procedure that puts emphasis on the role of the service customer/ user.

The paper aims at the development of a goal modelling approach for the analysis of collaborative value creation. Goal modelling is appropriate for this because it emphasizes on the intentions and the motivation of the actors and highlights the interdependencies between their goals and their practices [2]. Hence, it can describe the sharing of goals and resources and the need for collaboration between the different actors and their stakeholders. Goal modelling, as an early-phase requirement engineering method, aims at the clarification and the better understanding of the domain knowledge, emphasizes on business concepts and can support the analysis of business concerns in the analysis and design of collaborative processes and systems.

\section{Value Co-creation in Collaborative Networks}

The concept of value and the process of value creation has gained great interest in the literature of collaborative networks. Collaborative networks can be seen as 'value networks' in which a group of organizational entities work together to co-create different forms of value [3]. Preeminent in the literature is the study of value creation in collaborative networks in the industrial setting [1]. Some studies have also paid attention to the role of the customer, especially with regard to mass customization, personalization, customer integration and open innovation [3]. In general, collaborative networks can create value propositions that can address the needs of their shareholders, the end-customer, their members and the external markets [4].

In this paper we build on the contemporary literature of service management that regards service value as a collaborative procedure that features the key role of the customer. We wish to fertilize the research field in collaborative networks with the introduction of concepts that reveal the underpinnings of the value creation procedure and introduce a customer-oriented perspective that draws attention to the use of 
service as the critical stage in value creation. Notice that in the recent years collaborative networks have been applied beyond manufacturing to become relevant to a variety of business settings. For instance, collaborative networks are present in ecommerce since many years with the development of collaborative commerce (ccommerce) [5], while recently social commerce has emerged as a new type of ecommerce model that includes also the consumers, who participate in collaborative procedures with service providers and other partners for the co-creation of content, services and value [6].

Major contribution derives from the Service Dominant (SD) Logic [7, 8]. Value co-creation is defined as a resource-integrating, reciprocal-service providing process among actors who co-create value through holistic, meaning-laden experiences in nested and overlapping service ecosystems, governed and evaluated through their institutional arrangements [8]. It is notable that providers do not create and deliver value by themselves, but they support their customers in their value creating processes. Therefore, service providers can only make value propositions and provide service as input to the value co-creation process with the customers. If the proposition is accepted, value is co-created in concert with the customer and in the customer's context [7]. Hence, value is defined as value 'value-in-use' and 'value-in-context'/ 'value-in-social-context' [8].

Another prevalent approach, Service Logic [9], suggests value can take place in three spheres: a) the provider's sphere, where the firm produces resources and performs processes for the customers and, thus, facilitates customer's value creation, b) the customer sphere, where the customer creates value as value-in-use, independently of the provider, by integrating resources and adding self-resources, and c) the joint or co-creation sphere, where the customer interacts with the provider for the co-creation of value. Hence, value creation is the customer's process of extracting value from the use of service and value co-creation refers to the direct collaboration between the customer and the provider for the creation of value.

The customer-oriented perspective is further stressed in Customer-Dominant (CD) Logic [10] that regards services as embedded in customer's life practices and shifts the focus to what the customers are doing with services and how they involve services in their daily life practices. Value is driven by customer activities and is influenced/ facilitated by the actions of other actors (providers, other customers, friends, etc.). The 'customer ecosystem' augments a service ecosystem with the dimensions of the social reality and the physical and mental identity of the customer.

In sum, these approaches enlighten different aspects of service roles and interactions and allow developing a global understanding of service systems in order to create successful business models and architectures. Basic difference between the SD Logic and the Service Logic is the divergent conception of service interactions: while SD Logic zooms out and studies the relationships between actors that share service flows in service ecosystems, Service Logic zooms into the dual relationship between the customer and the provider and aims to provide a managerial perspective. $\mathrm{CD}$ logic, on the other hand, refocuses and places the interest on the customer, rather than on the service itself, the provider or the service system, and suggests seeing service interactions from the point of view of the customer. 


\section{Goal-oriented Requirements Engineering}

Requirements engineering (RE) is the initial phase in the process of system engineering that refers to the definition and the analysis of the needs a system has to fulfil. Goal-oriented requirements engineering (GORE) uses 'goals' as the basic conceptualization in order to elicit, model, and analyze requirements [11]. In the recent years the interest for GORE has increased and goal modelling has been incorporated into several RE frameworks [12], because the ultimate criterion for the evaluation of the success of a system is that it can meet the goals and address the concerns of the users and other stakeholders [13]. The key question in GORE is therefore 'why' something is happening, while the key objective is to understand the motivations, intentions and rationales of the system's users and stakeholders. Such an approach enables also revealing conflicts and identifying alternative solutions.

There are several approaches in GORE [12]. In this paper we use i-star (i*) [13] because it is a well-established and widely-practiced approach [12] that can fit well to and accommodate several characteristics of the value co-creation literature.

The central role in i-star is the Actor and the central concept is his/her Goals. Actors depend on others for the fulfilment of their goals - but they may also fall short in their intentions because other actors (partners) may fail to deliver the necessary outcomes. Actors are considered as 'strategic' and 'social' [13] because they seek opportunities and aim at rearrangements of their environment that could serve better their interests and they operate (interact) in social structures (e.g. organizations, markets, collaborative networks) that are governed by social conventions/institutions.

The i-star framework captures requirements by analyzing the strategic relationships between actors. It uses two types of models [13]: a) Strategic Dependency (SD) models, and b) Strategic Rationale (SR) models. SD models address the early-phase requirements analysis; they focus on the dependency between actors, i.e. what actors require from other actors in order to achieve their goals, and represent thus a network of intentional dependencies, which belong in four types: goal, softgoal, task and resource dependencies. SR models proceed with the systematic refinement of goals identified in SD models to explore ways for achieving them, a task that is addressed in later phases of requirements analysis. There are three types of relationships: a) task-decomposition, b) means-end, and c) contribution. A means-end relationship indicates a relationship between an end (it can be a goal or a softgoal, a task to be performed or a resource to be produced) and a means for attaining it; a task decomposition relationship analyses a task into its subcomponents; a contribution relationship shows the positive or negative effect of softgoals to the achievement of goals or the execution of tasks.

\section{A Goal Meta-model for Value Co-creation}

GORE and the i-star modelling methodology are appropriate for the analysis of value co-creation. GORE aims at understanding the motivations, intentions and rationales of the actors and stakeholders in the way they pursue their goals. Goals are related to 
value, as the achievement of a goal certainly brings value to the actor. The relationship between goals and value was also discussed elsewhere in this paper.

Goal models in i-star can highlight the structural, strategic and interactive aspects of collaborative networks. In particular, SD models can a) accommodate the various actors and roles that participate in a collaborative network, and b) represent and analyze the interdependencies in their efforts to achieve their goals. SR models on the other hand can emphasize on the analysis of the dependencies on the tasks and resources and highlight the procedural rationale and the requirements for the achievement of goals and the creation of value.

With regard to value co-creation in service research, the basic conceptualization of service as activities performed in order to bring benefit to somebody else [7] and the premise that the service user, as beneficiary, is always co-creator of value reveals that the service user interacts with and depends on the service provider and other social actors $[8,10]$ for receiving the expected service benefit. In i-star the focus is on the analysis of dependency relationships, while the notion of softgoals can express the preferences and qualitative requirements of the actors and therefore the idiosyncratic aspects of value [7]. Therefore, goal models can be used for the general representation of the value co-creation procedure.

In Fig. 1 we present a goal meta-model of the major concepts of value co-creation. It includes five types of actors: the Service User/ Customer, the Service Provider, the Provider's Partners, the Social Actors and the Institutions that govern service ecosystems. We adopt the ecosystemic approach of SD logic [8] and go beyond the direct relationship between the Customer and the Provider to include also the Customer's ecosystem [10], with the inclusion of the Social Actors, as well as the Provider's business ecosystem, in order to indicate that service development takes place in complex value chains and networks. Institutions are included as an abstract actor that provides the institutional framework for the operation of the service ecosystem by creating the necessary Institutional Arrangements [8].

The central relationship is between the Customer and the Provider. Each actor has a major goal in this relationship, the achievement of which depends on the other actor. The goal of the Customer is to Create Service Value, that is value through the use of service received from the Provider. The goal of the Provider is to have his Value Proposition Accepted by the Customer, which is prerequisite for selling service to the Customer and, thus, achieving other more basic business goals (e.g. making revenue).

The Customer and the Provider depend on each other also for the Service Cocreation (it is a task, not a goal in itself), that is the participation of the Customer in the procedures of the Provider for the development of the service. Fig. 1 shows that the Customer depends on the Provider, meaning that the customer wishes to participate in the service development procedure; however, the relationship could be reverse when the Provider requires the participation of the Customer in the procedure.

The major goal of the Customer in service interactions is to Create Service Value. It occurs as a result of Use of Service (task), which is a procedure performed in the customer context. Hence, Value Creation has the characteristics of value-in-use and value-in-context. Value creation depends on the Provider only in a general/ abstract way, as it is not directly related to any particular function, task or resource of the 
Provider. This way we denote the role of the Provide in value co-creation is universal [8], while his contribution can be direct or indirect [9].

The Use of Service can potentially require to Co-create/ Co-produce Service in close collaboration with the Provider and thus it depends on the Provider's Service Development process. The Use of Service by the Customer is a particular way of Integrating Resources in order to Create Service Value and address the needs and requirements of the daily life practices. In particular, the Use of Service refers to case that service is acquired from Providers to be used for the Creation of Service Value. The Customer can integrate other resources as well that he/she owns, such as his/ her experience and personal knowledge and skills. As the Customer operates in a social context, he/she can integrate and use also Resources (e.g. supplementary services, information, knowledge, competencies, comments, suggestions, etc.) received from Social Actors (family members, friends, colleagues, peers), in a similar way that receives and uses service (as a resource) from Service Providers. In sum, the Customer attains the goal of Service Value Creation by Integrating Resources and Service Value Creation requires the Use of Service among the resources to be integrated.

The Customer has two additional goals, to Appraise Service Value and to Perform Life Practices. The Customer Appraises Service Value being based on the personal Preferences and the Social Norms (attitudes, beliefs, trends, etc.) that prevail in the social environment and govern the operations of the Social Actors; hence, service value is manifested as value-in-social-context [8]. The Customer performs the daily Life Practices according to his/ her Needs, while depends on the Social Norms and the Institutional Arrangements that govern and guide the personal life practices and the social life practices.

The major goals of the Service Provider are to Develop Service and to Make a Value Proposition (of the service) that will be accepted by the Customer. These goals refer to the basic function of business organizations to produce and sell, respectively. Both these goals get operationalized by various Business Practices. The acceptance of the Value Proposition depends on the degree it meets the Needs and Preferences of the Customer. Once the Value Proposition is accepted, the Provider facilitates, directly or indirectly, the value creation process of the Customer. For instance, a particular method for the direct facilitation of the Customer is to Co-Produce service, which is depicted in Fig 1. There can be additional ways for the Customer facilitation in the use of service, either directly or indirectly [9].

The Provider collaborates with Business Partners in order to Develop Services. The Provider is also a resource integrator in performing his mission and in creating business value [8]. Here we focus on the value creation process for and with the Customer and do not get in details in the collaboration between the Provider and his Business Partners for the performance of the Business Practices. The Value Proposition and in general the business and marketing practices of the Provider are shaped and affected by Institutional Arrangements.

Certain key concepts of the literature, such as value co-creation, value-in-use and value-in-context, are not depicted in the goal meta-model. The reason is that a goal model emphasizes on the actor's goals and their dependencies. These concepts are not explicit goals, but they occur as the result of the interaction, the interdependencies and the collaboration of the actors. For instance, in the proposed goal meta-model, value 
co-creation occurs as a result of the interaction between the Customer and the Provider to achieve their particular goals, i.e. Creating Service Value and having the Value Proposition Accepted respectively.

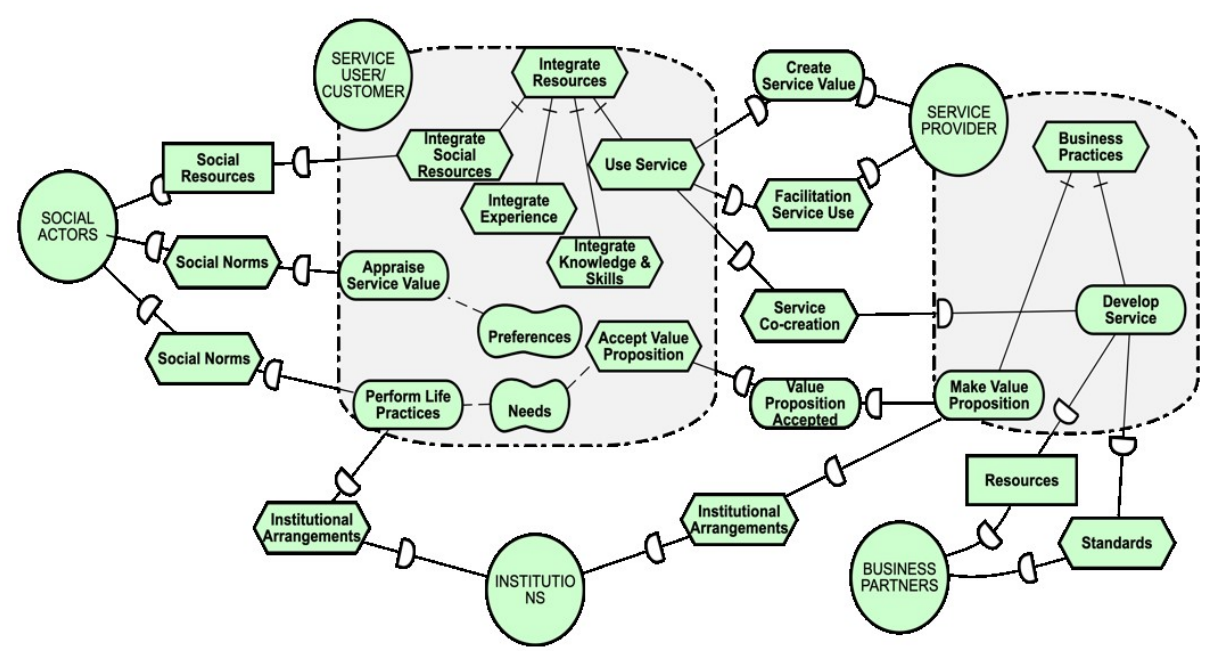

Fig. 1. A Goal Meta-model of Value Co-creation

\section{Conclusions}

The concept of value co-creation has been extensively discussed in the literature, but mostly in an abstract way that does not explicate several practical aspects. Hence, it is not clear how does value co-creation take place, under what circumstances, who does contribute and in what way, when it succeeds or fails, why it succeeds or fails, what alternatives can be pursued, etc. Moreover, value co-creation has not been addressed by requirements analysis and especially by formal modelling techniques. This paper addressed these shortcomings in the literature by attempting to apply the goal modelling technique for the analysis of value co-creation.

Goal modelling can be a promising method for the analysis of value co-creation because it can accommodate many key notions of the literature of value co-creation: it is based on the concept of the goal that is pertinent to the concept of value as the goal carries intrinsic value, it emphasizes on the goal achievement of the actors and especially on the interactions and the interdependencies between the actors during their goal seeking behavior, and it recognizes the role and the contribution of several actors and stakeholders that may have a role in the design and the function of complex structures, such as service ecosystems and collaborative networks. Hence, goal modelling can provide the baseline for the requirements analysis and design of service systems. In this paper we suggest the behavior and the operation of the actors in order to achieve their goals can be seen as a value creation behavior and moreover it can be 
seen as a value co-creation procedure, since the goal achievement is based on the collaboration and the interdependencies between the actors.

The paper proposes a goal meta-model of value co-creation in collaborative networks that can serve to the better understanding of value co-creation and the analysis of value co-creation procedures in real world situations. As an early-phase requirements engineering method, goals models can be used for the analysis of the needs and the business requirements of digital systems that support value co-creation. Goal models can be supplemented with other modelling techniques for the design and implementation of procedures and services in collaborative business architectures in e-business and in e-commerce that require and support value co-creation procedures (e.g. collaborative commerce, or social commerce).

\section{References}

1. Camarinha-Matos, L.M., Afsarmanesh, H., Galeano, N. and Molina, A.: Collaborative Networked Organizations: Concepts and Practice in Manufacturing Enterprises. Computers \& Industrial Engineering, 57(1), pp.46-60 (2009). https://doi.org/10.1016/i.cie.2008.11.024

2. Yu, E., Mylopoulos, J.: Why Goal-oriented Requirements Engineering. Proc. 4th Int. Workshop on Requirements Engineering, Vol. 15, pp. 15-22 (1998).

3. Romero, D. Molina, A.: Collaborative Networked Organisations and Customer Communities: Value Co-creation and Co-innovation in the Networking Era. Production Planning \& Control, 22(5-6), pp.447-472 (2011).

4. Bititci, U.S. Martinez, V. Albores, P. Parung, J.: Creating and Managing Value in Collaborative Networks. International Journal of Physical Distribution \& Logistics Management, 34 (3/4), pp. 251-268 (2004).

5. Hartono, E. Holsapple, C.: Theoretical Foundations for Collaborative Commerce Research and Practice. Information Systems and E-business Management, 2(1), pp.1-30 (2004).

6. Huang, Z. Benyoucef, M.: From E-commerce to Social Commerce: A Close Look at Design Features. Electronic Commerce Research and Applications, 12(4), pp.246-259 (2013).

7. Vargo, S. L., Lusch, R. F.: Service-Dominant Logic: Continuing the Evolution. Journal of the Academy of Marketing Science. 36(1), pp. 1-10 (2008).

8. Vargo, S.L. Lusch, R.F.: Institutions and Axioms: An Extension and Update of ServiceDominant Logic. Journal of the Academy of Marketing Science, 44(1), pp.5-23 (2016).

9. Grönroos, C. Ravald, A.: Service as Business Logic: Implications for Value Creation and Marketing. Journal of Service Management, 22 (1), pp. 5-22 (2011).

10. Heinonen, K., Strandvik, T.: Customer-Dominant Logic: Foundations and Implications. Journal of Services Marketing, 29(6/7), pp. 472-484 (2015).

11. Van Lamsweerde, A.: Goal-oriented Requirements Engineering: A Guided Tour. Proc. of 5th IEEE International Symposium on Requirements Engineering, pp. 249-262 (2001)

12. Horkoff, J. Aydemir, F.B. Cardoso, E. Li, T. Maté, A. Paja, E. Salnitri, M. Piras, L. Mylopoulos, J. Giorgini, P.: Goal-oriented Requirements Engineering: An Extended Systematic Mapping Study. Requirements Engineering, 24(2), pp.133-160 (2019).

13. Yu, E.: Towards Modeling and Reasoning Support for Early-Phase Requirements Engineering. In Proceedings of RE-97, 3rd Int. Symp. on Requirements Engineering, Annapolis, pp. 226-235 (1997). 